\title{
Intracranial hypertension in Africans with cerebral malaria
}

Kenya Medical Research Institute, Clinical Research Centre, Kilifi, Kenya and Department of Paediatrics, University of Oxford

C R J C Newton

Kenya Medical

Research Institute, Clinical Research

Centre, Kilifi, Kenya and Nuffield

Department of Clinica

Medicine, University

of Oxford

J Crawley

M English

K Marsh

Kenya Medical Research Institute, Clinical Research

Centre, Kilifi, Kenya and Department of

Pharmacology and

Therapeutics,

University of Ibadan,

Nigeria

A Sowumni

Kenya Medical

Research Institute,

Clinical Research

Centre, Kilifi, Kenya

C Waruiru

I Mwangi

Kenya Medical Research Institute, Clinical Research Centre, Kilifi, Kenya and Department of

Pharmacology and

Therapeutics,

University of Liverpool

S Murphy

P A Winstanley

Neurosciences Unit, Institute of Child

Health, University

College London,

London

F J Kirkham

Correspondence to:

Dr C R J C Newton,

Neurosciences Unit, The

Wolfson Centre,

Mecklenburgh Square,

London WC1N 2AP.

Accepted 2 October 1996

C R J C Newton, J Crawley, A Sowumni, C Waruiru, I Mwangi, M English, S Murphy, P A Winstanley, K Marsh, F J Kirkham

\begin{abstract}
The causes of death and neurological sequelae in African children with cerebral malaria are obscure. Intracranial pressure (ICP) was monitored and cerebral perfusion pressure (CPP) calculated in 23 Kenyan children with cerebral malaria. Four children had severe intracranial hypertension (ICP $>40 \mathrm{~mm} \mathrm{Hg}$, CPP $<40$ $\mathrm{mm} \mathrm{Hg}$ ): two died, one with an ICP of 158 $\mathrm{mm} \mathrm{Hg}$ and signs of transtentorial herniation, the other one with an ICP of $42 \mathrm{~mm}$ $\mathrm{Hg}$ and cardiorespiratory arrest. The other two survived with severe neurological sequelae. Nine had intermediate intracranial hypertension (ICP $>\mathbf{2 0}$ $\mathrm{mm} \mathrm{Hg}$, CPP $<50 \mathrm{~mm} \mathrm{Hg}$ ) and $10 \mathrm{had}$ mild intracranial hypertension (maximum ICP 10-20 mm Hg); all survived without severe sequelae. Mannitol controlled the ICP in children with intermediate intracranial hypertension, but it did not prevent the development of intractable intracranial hypertension in children with severe intracranial hypertension. Intracranial hypertension is a feature of Kenyan children with cerebral malaria and severe intracranial hypertension is associated with a poor outcome.

(Arch Dis Child 1997;76:219-226)
\end{abstract}

Keywords: cerebral malaria; intracranial pressure.

Cerebral malaria is probably the most common paediatric encephalopathy in sub-Saharan Africa, accounting for many of the estimated 1000000 childhood deaths from falciparum malaria each year ${ }^{12}$ and producing neurological deficits in a further 40000 children per year. ${ }^{3}$ The causes of poor outcome in these children are largely undetermined.

Intracranial hypertension is an important determinant of poor outcome in other nontraumatic paediatric encephalopathies ${ }^{4-9}$ and aggressive treatment with agents such as mannitol is thought to improve the outcome in Reye's syndrome. ${ }^{8}$ Opening lumbar puncture pressures are raised in African children with cerebral malaria ${ }^{10-12}$ and we have documented clinical features compatible with transtentorial herniation in children who died, ${ }^{10}$ although the significance of these findings has been questioned..$^{13}$ A relatively simple intervention, such as an osmotic agent may improve the outcome of a large number of children with cerebral malaria. Thus we monitored intracranial pressure (ICP) in children with severe cer- ebral malaria, to describe the pattern of intracranial hypertension and to determine the efficacy of mannitol in lowering ICP.

\section{Patients and methods}

This study was conducted at Kenya Medical Research Institute (KEMRI), Kilifi District Hospital, Kenya between May 1992 and August 1994. Ethical permission for the study was granted by the KEMRI/National Ethical Review Committee and written informed consent was obtained from the child's parents.

Children who fulfilled the World Health Organisation's criteria for cerebral malaria, that is patients who are unconscious (defined as the inability to localise pain), have asexual Plasmodium falciparum parasites detected in their blood, and other causes of an encephalopathy such as bacterial meningitis excluded, ${ }^{15}$ were assessed for ICP monitoring. Permission for monitoring was requested if the child was normoglycaemic, and had one of the following clinical signs at least an hour after the last seizure: (i) best motor response-sluggish flexion to a painful stimulus, (ii) decerebrate/ decorticate posturing, (iii) dilated and sluggish pupils, or (iv) absent oculocephalic reflexes. Children were not monitored if there was (i) a platelet count $<40 \times 10^{9} / 1$, (ii) evidence of spontaneous bleeding or (ii) severe metabolic acidosis $(\mathrm{pH}<7.1$ with base excess $<-10)$.

ICP was monitored with a fibreoptic system (model 110-4B, Camino Laboratories, San Diego, USA) inserted into the subarachnoid space. The wave form was verified on an HP-7834A monitor (Hewlett Packard, Andover, USA) and the opening ICP was noted. Mean arterial pressure (MAP) was measured with an intra-arterial line and cerebral perfusion pressure (CPP) was calculated from the MAP-ICP. The data were recorded at intervals of 15 minutes or less. The monitor was removed if the ICP was less than $20 \mathrm{~mm} \mathrm{Hg}$ for longer than 12 hours, or if the child could localise pain. A lumbar puncture was performed shortly before the ICP monitor was removed to exclude bacterial meningitis. Computed tomography was performed in 15 children after the removal of the monitor.

\section{GENERAL TREATMENT}

Children were randomised to receive either intravenous quinine dihydrochloride (loading dose $20 \mathrm{mg} / \mathrm{kg}$ infused over four hours, followed by $10 \mathrm{mg} / \mathrm{kg}$ every eight hours) or intramuscular artemether $(3.2 \mathrm{mg} / \mathrm{kg}$ intramuscularly, followed by $1.6 \mathrm{mg} / \mathrm{kg}$ daily), as 
part of a multicentred clinical trial (results in preparation). Antimicrobials were administered until a lumbar puncture was performed. ${ }^{10}$

Intravenous $0.18 \%$ normal saline $/ 4 \%$ dextrose was infused at a rate of $3 \mathrm{ml} / \mathrm{kg} /$ hour after initial resuscitation. Seizures were treated initially with intravenous diazepam $(0.3 \mathrm{mg} / \mathrm{kg})$ or intramuscular paraldehyde $(0.1 \mathrm{ml} / \mathrm{kg})$, and if they persisted, with intravenous phenytoin $(15-20 \mathrm{mg} / \mathrm{kg})$ or intramuscular phenobarbitone $(15-20 \mathrm{mg} / \mathrm{kg})$. Blood transfusions $(15-20 \mathrm{ml} / \mathrm{kg})$ were given if the packed cell volume was below 0.15 and the child had signs of respiratory distress. Hypoglycaemia (whole blood glucose $<2.2 \mathrm{mmol} / \mathrm{l}$ ) was treated with $0.6 \mathrm{ml} / \mathrm{kg}$ of $50 \%$ dextrose.

Children were nursed supine, with the head flat and in the midline position. The stomach contents were drained via a nasogastric tube. The children had six hourly neurological evaluations, with depth of coma assessed by the paediatric modification of the Glasgow coma scale, the Adelaide coma scale, until they recovered from coma (able to localise pain) or died. None of the children was ventilated.

TREATMENT OF RAISED ICP

Mannitol (0.5-1.0 g/kg infused over $10-20$ minutes) was administered if: (i) ICP was above $20 \mathrm{~mm} \mathrm{Hg}$ for longer than 20 minutes, (ii) there were frequent spikes of ICP above 20 $\mathrm{mm} \mathrm{Hg}$ with less than a five minute interval between each, or (iii) CPP was less than $50 \mathrm{~mm}$ $\mathrm{Hg}$ for longer than 20 minutes. Dopamine was infused $(2.5-25 \mu \mathrm{g} / \mathrm{kg} / \mathrm{min})$ if mannitol did not raise the CPP above $50 \mathrm{~mm} \mathrm{Hg}$.

\section{DATA ANALYSIS}

The ICP and CPP findings were classified as follows: (a) severe intracranial hypertension: ICP above $40 \mathrm{~mm} \mathrm{Hg}$ and CPP less than 40 $\mathrm{mm} \mathrm{Hg}$ lasting longer than 15 minutes continuously, (b) intermediate intracranial hypertension: ICP above $20 \mathrm{~mm} \mathrm{Hg}$ and CPP less than $50 \mathrm{~mm} \mathrm{Hg}$ lasting longer than 15 minutes continuously, (c) mild intracranial hypertension: maximum ICP $10-20 \mathrm{~mm} \mathrm{Hg}$ and minimum CPP above $50 \mathrm{~mm} \mathrm{Hg}$, and (d) normal intracranial pressure: maximum ICP less than $10 \mathrm{~mm} \mathrm{Hg}$ and minimum CPP above $50 \mathrm{~mm} \mathrm{Hg}$.

ICP waves were identified according to the following criteria: (i) A waves, abrupt rise in ICP to above $50 \mathrm{~mm} \mathrm{Hg}$ with the ICP remaining at this level for 5-20 minutes, before returning to the baseline ${ }^{16}{ }^{17}$; (ii) $\mathrm{B}$ waves, sharp peaked waves occurring at a frequency of 0.5 to 2 minutes ${ }^{16}{ }^{17}$; (iii) plateau-like waves, similar to A waves, but with an ICP of $20-50 \mathrm{~mm} \mathrm{Hg}$ at the plateau and (iv) 'tented waves', increases in ICP greater than $20 \mathrm{~mm} \mathrm{Hg}$, lasting 5-20 minutes. ${ }^{18}$

\section{Outcome}

Neurological outcome was classified as no sequelae (normal), mild/moderate sequelae (hemiparesis, learning difficulties), severe sequelae (spastic quadriparesis, intractable epilepsy and/or poor vision) or death. ${ }^{19}$ Poor outcome refers to children who survived with severe neurological sequelae or died and good outcome to the remainder.

\section{Statistical analysis}

Comparisons of proportions were performed with the two tailed Fisher's exact test, as the expected frequencies in the cells were $<5$. Differences are regarded as significant if the probability of the test statistic is $<5 \%$.

\section{Results}

CHILDREN MONITORED

From 1 December 1991 to 1 August 1994, 40 children were identified for ICP monitoring on the clinical criteria. Twenty three children had ICP monitors inserted. Four children were admitted during the absence of the personnel trained to insert the ICP monitor and five were not monitored because they were recruited for another study which precluded adequate supervision of ICP monitoring. The others were excluded because the parents refused consent $(n=1)$ or were not available to give consent $(n=2)$, or because of thrombocytopenia $(n=2)$ or severe metabolic acidosis $(n=3)$.

The clinical and laboratory features of the children who had ICP monitoring (arranged in order of increasing severity of intracranial hypertension) are shown in table 1 . None of the children had evidence of another central nervous system infection (that is, no growth from blood cultures; <5 leucocytes $\times 10^{6} / 1$ in cerebrospinal fluid (CSF), and CSF glucose greater than two thirds of the blood glucose). There were no serious complications from ICP monitoring; three of the 15 children who had computed tomography had tomographic evidence of small amounts of blood in the subarachnoid space and another child had a superficial wound infection at the site of the monitor.

ICP FINDINGS AND OUTCOME

All the children had intracranial hypertension with a maximum ICP above $15 \mathrm{~mm} \mathrm{Hg}$ (table 2). Four children had severe intracranial hypertension and nine had intermediate intracranial hypertension; in the other 10 children, the ICP was raised but did not rise above 20 $\mathrm{mm} \mathrm{Hg}$ for longer than 15 minutes. In two children the ICP monitor drifted by $-11 \mathrm{~mm}$ $\mathrm{Hg}$ over 18 hours (number 10) and by $16 \mathrm{~mm}$ $\mathrm{Hg}$ over 92 hours (number 21): although the patterns of intracranial hypertension were compatible with mild intracranial hypertension and severe intracranial hypertension, respectively, these data were not used for further analysis and not included in fig 1 . There was no difference between these groups in parasitaemia, haemoglobin, or lactate.

Opening ICP did not predict maximum ICP nor did opening CPP predict minimum CPP. A maximum ICP above $40 \mathrm{~mm} \mathrm{Hg}(\mathrm{p}=0.017$, Fisher's exact test) and CPP below $40 \mathrm{~mm} \mathrm{Hg}$ ( $p=0.009$, Fisher's exact test) were associated with a poor outcome (fig 1). There was no association between duration of history or duration of coma and the pattern of intracranial hypertension (table 1).

The children with severe intracranial hypertension all did badly: two died and the other 


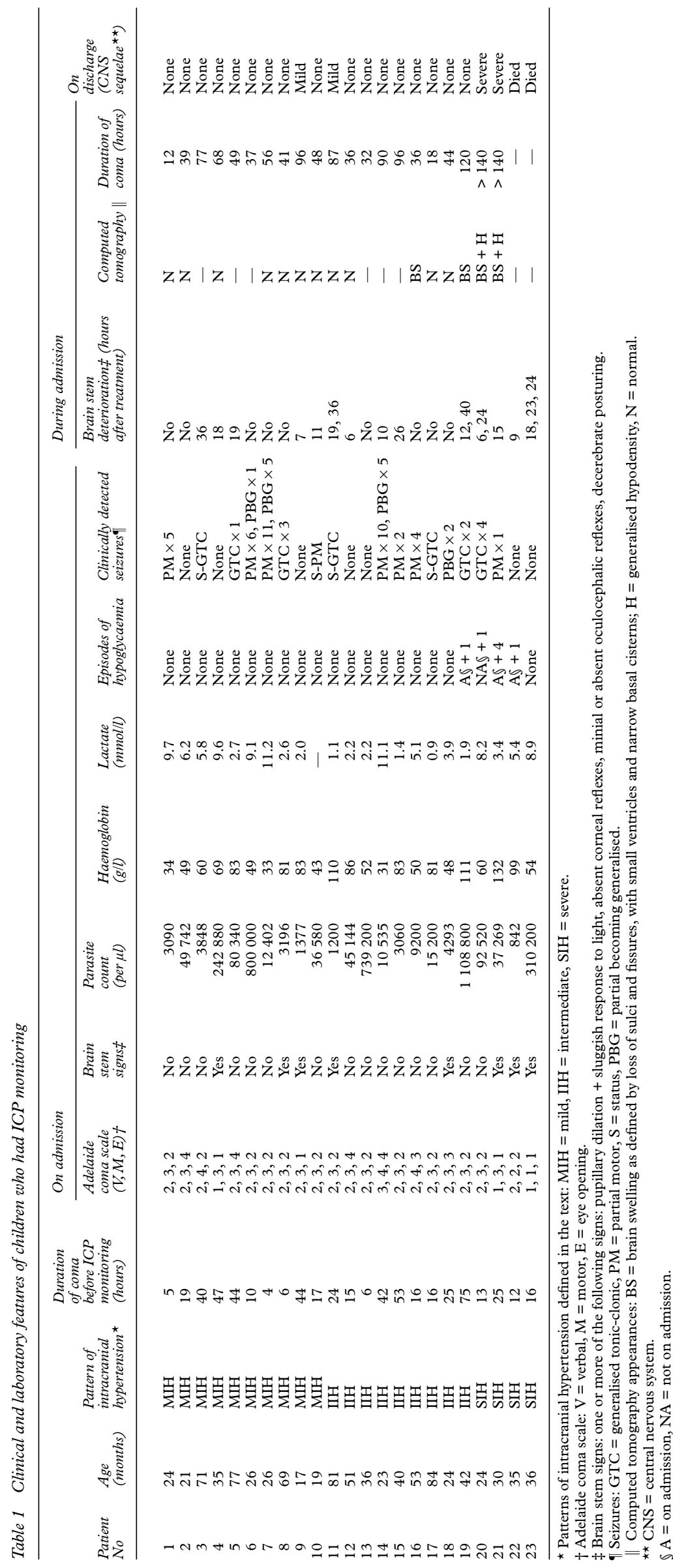

two had severe neurological sequelae. The children with severe sequelae had severe visual impairment, cognitive problems, and spastic quadriparesis. One child (number 20) was discharged in a vegetative state and died four months later with a respiratory illness, while the other child (number 21) showed little improvement after a year. Two children who presented with status epilepticus had mild or moderate sequelae; one with intermediate intracranial hypertension (number 11) recovered with learning difficulties, while another with mild intracranial hypertension (number 9) was discharged with a right sided hemiparesis, sensory inattention, and visual field defect. All the other children had a good outcome.

PATTERNS OF INTRACRANIAL HYPERTENSION (1) Severe intracranial hypertension

Four children developed severe intracranial hypertension, two of whom died. One child who died (number 23) was admitted with opisthotonic posturing and papilloedema. The opening ICP and CPP were $25 \mathrm{~mm} \mathrm{Hg}$ and $55 \mathrm{~mm} \mathrm{Hg}$. During the first 11 hours of monitoring, three doses of mannitol were given and the ICP was maintained below 30 $\mathrm{mm} \mathrm{Hg}$, with the CPP above $55 \mathrm{~mm} \mathrm{Hg}$ (fig 2). Thereafter the ICP rose inexorably, despite two additional doses of mannitol, to an agonal peak of $153 \mathrm{~mm} \mathrm{Hg}$ (CPP, $2 \mathrm{~mm}$ $\mathrm{Hg}$ ). During this period, the child developed clinical evidence of transtentorial herniation; initially he had features of the uncal syndrome $^{10}$ and then progressed to the medullary syndrome shortly before his death. The other child who died (number 22) had an opening ICP of $28 \mathrm{~mm} \mathrm{Hg}$ and CPP of $75 \mathrm{~mm} \mathrm{Hg}$. The first dose of mannitol only reduced the ICP from 30 to 24 $\mathrm{mm} \mathrm{Hg}$ (CPP remained unchanged at 50 $\mathrm{mm} \mathrm{Hg}$ ), during which child developed ataxic respiration. Thereafter the CPP fell despite dopamine infusion. The second dose of mannitol was administered 15 minutes before the child had a terminal cardiorespiratory arrest.

The other two children with severe intracranial hypertension (numbers 20 and 21) had similar patterns of intracranial hypertension: they had an opening ICP of $13 \mathrm{~mm} \mathrm{Hg}$ and $9 \mathrm{~mm} \mathrm{Hg}$, respectively, and an initial period of 10-12 hours during which the ICP was less than $20 \mathrm{~mm} \mathrm{Hg}$, after which they developed intractable intracranial hypertension. In one child (number 20) the maximum ICP and minimum CPP were recorded at 33 hours and 97 hours after the onset of monitoring. The other child (number 21) was admitted with hypoglycaemia and hypotension but the maximum ICP and minimum CPP could not be determined accurately. The monitor was removed from these children when they became neurologically stable.

Pressure waves (B and 'tented' waves) were detected in three of the children with severe intracranial hypertension, but were 


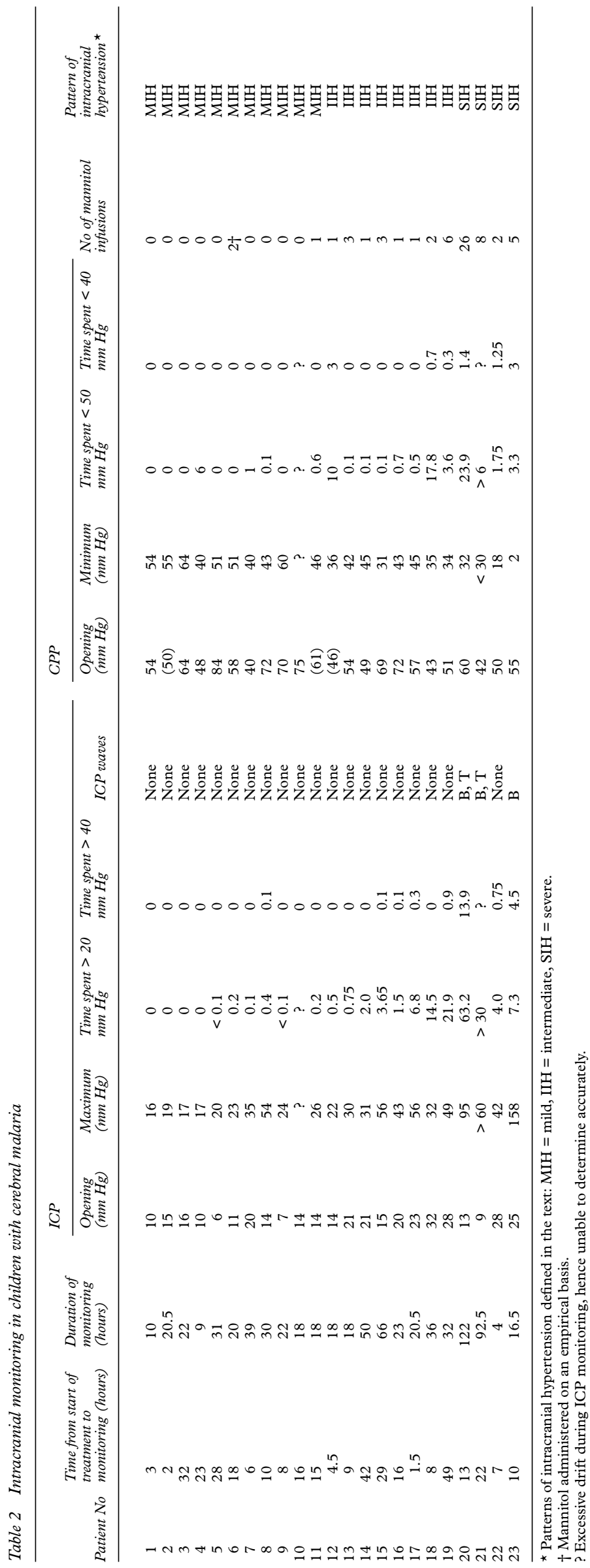

not seen in the child who died of a cardiorespiratory arrest (number 22). One child (number 20) had seven episodes of B waves, of which two were associated with the development of sluggish dilated pupillary response to light, hypertonia, and hyperventilation. In the other children the B waves were not associated with clinical signs.

Infusion of mannitol was followed by a reduction in the ICP in all instances. On eight occasions in the three children with quantitative data, mannitol did not reduce the ICP to below $20 \mathrm{~mm} \mathrm{Hg}$. In patient number 20, the time of the lowest ICP after the infusion was a median of 46 (range 10-99) minutes and on the occasions it fell below $20 \mathrm{~mm} \mathrm{Hg}$, the time it took to return to $20 \mathrm{~mm} \mathrm{Hg}$ was a median of 97 (range 11-179) minutes. In the children who died, mannitol caused only a transient reduction in ICP and did not prevent one child (number 23) from developing signs of the medullary stage of herniation (fig 2) or the other child (number 22) dying.

(2) Intermediate intracranial hypertension The nine children with intermediate intracranial hypertension had a median opening ICP of 21 (range 14-32) $\mathrm{mm} \mathrm{Hg}$ and median maximum ICP of 32 (range 22-56) $\mathrm{mm} \mathrm{Hg}$, at a median of 51 (range 12-63) hours after onset of treatment. Mannitol reduced the ICP in all cases, reaching a median of $10 \mathrm{~mm} \mathrm{Hg}$ (range 4-17), but rising to above $20 \mathrm{~mm} \mathrm{Hg}$ in 120 (range 50-180) minutes on nine occasions (table 2).

\section{(3) Mild intracranial hypertension}

In the 10 children with mild intracranial hypertension the median opening ICP was 14 (range 10-16) $\mathrm{mm} \mathrm{Hg}$ and the median maximum ICP 19.5 (range 16-54) $\mathrm{mm} \mathrm{Hg}$. The children were monitored for a median of 22 (range 9-39) hours. One child was given mannitol on an empirical basis.

\section{RELATIONSHIP OF ICP TO CLINICAL SIGNS (1) Clinical signs predicting pattern of intracranial hypertension}

A sluggish or absent pupillary response, detected before monitoring, was associated with the development of intermediate or severe intracranial hypertension ( $p=0.003$, Fisher's test), while other signs (such as absent or extensor motor response, pupillary dilatation, decerebrate posturing, or absent oculocephalic reflexes) were not. In the group of 14 children in whom all the components of the Adelaide coma scale were tested every six hours, a worst summated score before monitoring of less than 6 was associated with the development of severe intracranial hypertension $(\mathrm{p}=0.038$, Fisher's test).

\section{(2) Clinical signs during monitoring}

The most reliable signs of ICP spikes were dilated pupils, which responded sluggishly to light. In one child (number 19), the left pupil dilated and reacted sluggishly to light when the ICP rose above $40 \mathrm{~mm} \mathrm{Hg}$, became smaller and reacted more briskly after the spike, and 

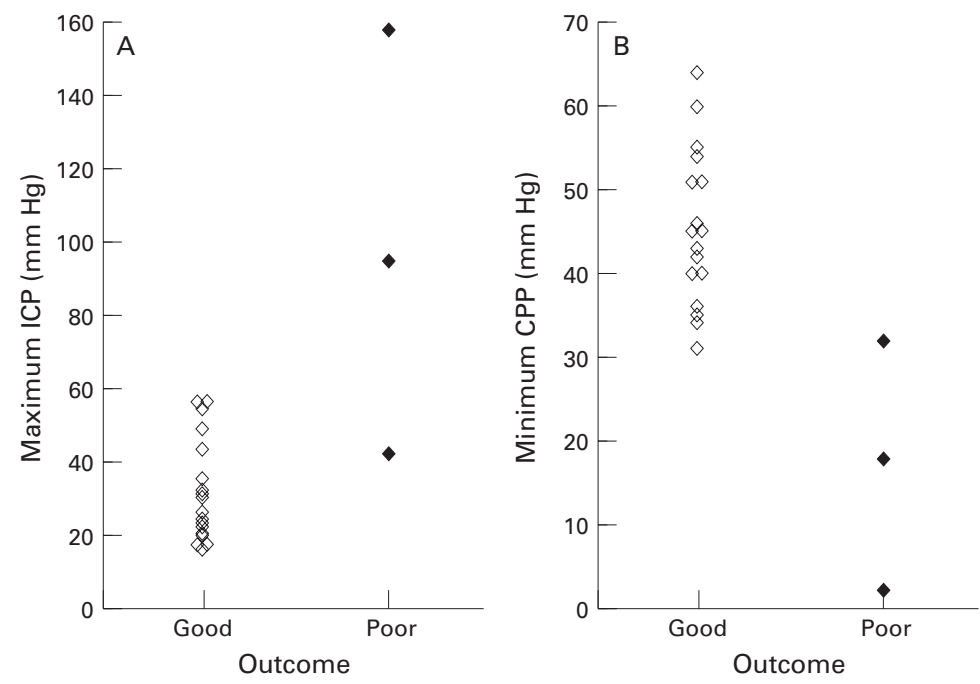

Figure 1 Relationship between $(A)$ maximum ICP and $(B)$ minimum CPP and outcome. The measurements of children without accurate quantitative data (numbers 10 and 21) are not shown.

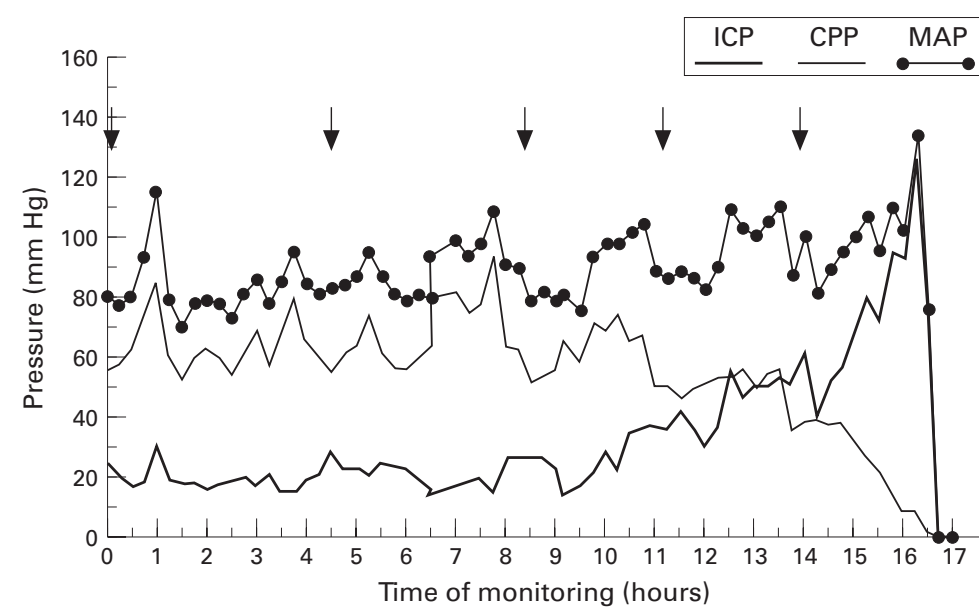

Figure 2 ICP record in the child (number 23) who died during monitoring. Mannitol was infused (arrows) on five occasions.

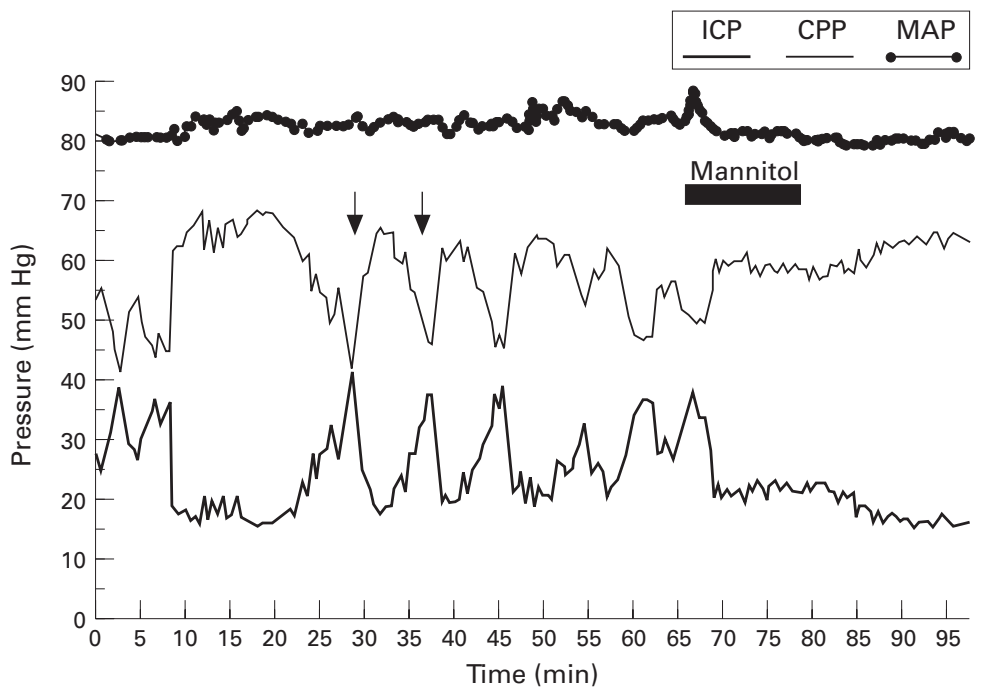

Figure 3 ICP record of a child with intermediate intracranial hypertension (number 19), showing 'tented'waves associated with sluggish dilated pupils (arrows), which disappeared with the infusion of mannitol (black rectangle). returned to normal after the administration of mannitol (fig 3). Papilloedema developed in two children with severe intracranial hypertension: it was present on admission in one of the children who died (number 23) and it appeared after severe intracranial hypertension developed in the other child (number 20). There was an association between papilloedema and severe intracranial hypertension ( $p=0.024$, Fisher's test), but not between fundal haemorrhages and severity of intracranial hypertension. Twenty three episodes of decerebrate posturing occurred in five patients (numbers 7, 10,11, 17, and 21). The ICP immediately before the onset of the posturing was a median of $23 \mathrm{~mm} \mathrm{Hg}$ (range 11-28) and rose to a median of 28 (range 12-49) $\mathrm{mm} \mathrm{Hg}$ during the posturing.

(3) ICP and seizures

Eighty one seizures were detected clinically in nine children during monitoring. Seizures were associated with transient increases of ICP often persisting after the clinical manifestations had ceased. The ICP rose by a median of $+154 \%$ (range +88 to $+467 \%$ ) and CPP changed by $-3 \%$ (range -46 to $+9 \%$ ) with generalised seizures. In partial seizures, the ICP rose by a median of $54 \%$ (range +40 to $+150 \%$ ) and the CPP fell by a median of -12 (range -30 to + 36). In three children with intermediate intracranial hypertension and status epilepticus (numbers 11, 17, and 18), the ICP decreased to less than $20 \mathrm{~mm} \mathrm{Hg}$ after the seizures were controlled.

ICP AND LABORATORY VARIABLES

There was no association between opening ICP, maximum ICP, or pattern of intracranial hypertension and blood tests on admission (parasitaemia, haemoglobin, carbon dioxide pressure, base excess, lactate, or glucose), CSF biochemistry (protein or lactate), which was sampled at the end of the ICP monitoring or choice of antimalarial.

\section{Discussion}

This study clearly shows that intracranial hypertension is a feature of cerebral malaria in African children and that severe intracranial hypertension is associated with a poor outcome. Critically high ICP developed in both children who died, one child had clinical signs of herniation, while the other had a cardiorespiratory arrest. Severe intracranial hypertension was also associated with severe neurological sequelae in two children. Although mannitol reduced ICP and appeared to control the ICP in children with intermediate intracranial hypertension, it neither prevented nor controlled severe intracranial hypertension.

There is a dilemma in the appropriateness of these high technical investigations in important health problems of countries with limited health resources. The justifications for the present study were (i) that despite the raised opening lumbar puncture pressures, these could not be used to predict maximum ICP, ${ }^{59}$ (ii) there was good clinical evidence for hernia- 
tion in children with cerebral malaria ${ }^{10}$ and therefore a relatively simple intervention, such as an osmotic agent may be beneficial, and (iii) we needed to ensure that the osmotic agent was effective in reducing ICP and determine the duration of action before proceeding to a randomised control trial.

Raised ICP causes death either by compressing the brain stem during transtentorial herniation or by causing global ischaemia. Although we were unable to perform necropsy on the children who died, one was observed to have clinical features of the uncal and medullary stages of herniation which developed as the ICP rose to the critically high pressures. Further evidence that intracranial hypertension contributes to the death of children with cerebral malaria is provided by our original report, in which children died with signs suggestive of brain stem herniation ${ }^{10}$ and another study, in which three of the six children with cerebral malaria who were monitored with transcranial Doppler had sonographic evidence of progressive intracranial hypertension, associated with the signs of herniation during their agonal stages. ${ }^{20}$ Finally, frank herniation has been observed at necropsy in a Nigerian child with cerebral malaria ${ }^{21}$ and has been detected by magnetic resonance imaging in Thai adults. ${ }^{14}$ However, several other mechanisms, including metabolic acidosis, anaemia, and hypoglycaemia may interact to cause death and the exact role of intracranial hypertension as a cause of death awaits further studies of ICP monitoring and neuropathology.

Raised ICP produces brain damage by causing global ischaemia due to reduction in CPP or by compromising flow in the basal cerebral arteries during transtentorial herniation. In children with non-traumatic coma a CPP of less than $40 \mathrm{~mm} \mathrm{Hg}$ is associated with a poor outcome..$^{5822}$ In this study, two children with severe neurological sequelae both had severe intracranial hypertension. One child (number 20) had a minimum CPP of $32 \mathrm{~mm} \mathrm{Hg}$ and had a watershed distribution of ischaemic damage on a later computed tomogram, while the other child (number 21) developed severe intracranial hypertension after he was admitted with severe hypotension and hypoglycaemia. Although another two children (numbers 9 and 11) also developed mild sequelae despite a minimum CPP of 60 and $46 \mathrm{~mm} \mathrm{Hg}$, both of these children had status epilepticus. The computed tomograms of children with cerebral malaria do not support the idea that sequelae are caused by herniation. ${ }^{23}$ Thus a low CPP appears to be associated with severe sequelae, although a causal relationship remains to be established.

The possible causes of intracranial hypertension in cerebral malaria are an increase in cerebral blood volume (CBV), cerebral oedema or acute hydrocephalus. An increase in CBV is most likely, ${ }^{10}$ since computed tomograms do not show any evidence of acute hydrocephalus or vasogenic oedema. ${ }^{23}$ Two children in this study had tomographic appearances compatible with cytotoxic oedema during recovery and were discharged with severe sequelae.
Recent magnetic resonance imaging studies from Thailand also suggest that there is an increase in CBV. ${ }^{14}$ The CBV could be increased by the sequestration of parasitised erythrocytes in the cerebral venules (the histopathological hallmark of cerebral malaria) or an increase in cerebral blood flow (CBF). The sequestered mass of parasitised erythrocytes may represent a diffuse space occupying lesion increasing the space the vascular compartment occupies within the cranium. Furthermore it may also impede venous outflow. Sequestration may be particularly important in African children, since they have higher peripheral parasitaemias than do non-immune adults with cerebral malaria ${ }^{15}$ and thus by implication (although not proved, since the sequestered mass cannot be measured in vivo) a larger sequestered mass in a smaller volume cranium. In this study, the lack of association between the peripheral parasitaemia and the pattern of intracranial hypertension does not necessarily refute this suggestion, since the analysis was performed on only 23 patients and the peripheral parasitaemia is less likely to reflect the sequestered mass in treated patients.

Besides sequestration, an increase in CBV could be caused by an increase in CBF. In this study generalised or prolonged partial seizures raised the ICP, probably by increasing $\mathrm{CBF}^{24}$ but also possibly by producing oedema. Anaemia increases the CBF by decreasing the viscosity and oxygen content of the blood. ${ }^{25}$ Tumour necrosis factor, which is raised in children with cerebral malaria, ${ }^{26} 27$ might also increase the $\mathrm{CBF}$ as it induces the release of nitric oxide, a potent vasodilator, and induces fever, which increases the cerebral metabolic rate. Lactic acidosis, a common feature of cerebral malaria, ${ }^{28}$ may be associated with an increase in CBF and luxury perfusion. ${ }^{29}$ The lack of association between the arterial carbon dioxide pressure and ICP suggests that vascular changes responsive to carbon dioxide are not the major determinants of raised ICP. Thus vascular factors are likely to be responsible for the raised ICP in most children with cerebral malaria, although cytotoxic edema would contribute to severe intracranial hypertension.

In these children, ICP monitoring was unique, in that the children were of necessity not paralysed. Disappointingly there were few clinical correlates of raised ICP; pupillary dilatation, particularly associated with a sluggish response to light, was the most reliable sign of a high ICP, although it was not specific and was not apparent during many of the episodes when the ICP was above $40 \mathrm{~mm} \mathrm{Hg}$. Furthermore, decerebrate posturing, often regarded as a sign of raised ICP, ${ }^{30}$ was present in two children when the baseline ICP was less than 20 $\mathrm{mm} \mathrm{Hg}$. As in other studies, ${ }^{59}$ we found that opening CSF pressures did not predict maximum ICP. These results clearly indicate that intracranial hypertension cannot be assessed by clinical examination, nor a single pressure measured at lumbar puncture.

The lack of clinical signs reflecting raised ICP makes the decision to institute ICP monitoring more difficult. Indications for monitoring ICP in 
other encephalopathies are variable, reflecting the lack of any controlled studies which show the benefits of ICP monitoring. Most paediatric authorities would institute ICP monitoring if the child was unconscious with a summated Glasgow coma score less than $8 .^{493132}$ As yet, there are not enough data to provide reliable indications for ICP monitoring in cerebral malaria, although children with an Adelaide coma score of less than 6 and pupillary abnormalities are more likely to develop or have more severe intracranial hypertension than those without these signs.

The main rationale for our studies on intracranial hypertension is to develop empirical regimens for the management of cerebral malaria in peripheral settings. In Africa, potential treatments for intracranial hypertension are limited to nursing care, appropriate fluid regimens, osmotherapy, steroids, and other pharmaceutical agents. Corticosteroids are ineffective in diffuse encephalopathies and were found to be detrimental in adults with cerebral malaria, ${ }^{33}{ }^{34}$ but have not been tested in African children. Osmotherapy has been used in children with cerebral malaria previously, but is not recommended by the World Health Organisation. ${ }^{15}$ One osmotic agent, $30 \%$ urea in $10 \%$ invert sugar, appeared to improve the outcome in Liberian children. ${ }^{35}$ Mannitol ( $1 \mathrm{~g} / \mathrm{kg}$ eight hourly) was reported to improve the level of consciousness ${ }^{36}$ and outcome ${ }^{37}$ in Ghanian children. However, the significance of these reports are difficult to determine, as these studies lacked appropriate controls.

A major question to arise from our observation is whether osmotherapy contributed to the outcome in the group with intermediate intracranial hypertension. In $74 \%$ of all the children the ICP was greater than $20 \mathrm{~mm} \mathrm{Hg}$ for more than 15 minutes, a level which would be actively treated in most intensive care units. All these children except one (number 8) were given mannitol and $70 \%$ had a good outcome. However establishing cause and effect is difficult. Furthermore it is not possible to determine if severe intracranial hypertension is a consequence of untreated intermediate intracranial hypertension, or whether severe intracranial hypertension reflects the development of widespread cerebral damage secondary to other concurrent pathogenic processes. As yet there are not enough data to recommend an empirical regimen for control of ICP.

In conclusion, intracranial hypertension is a consistent feature of cerebral malaria in Kenyan children, but its precise role in this encephalopathy still remains to be defined. Further ICP monitoring is required to determine the incidence of severe intracranial hypertension and to identify the most effective regimens to reduce ICP. The role of intracranial hypertension in causing death needs to be substantiated by further detailed neuropathological studies in African children. The question of whether intracranial hypertension is a treatable cause of death and sequelae, or merely an epiphenomenon, can only be answered by large randomised trials of an effective intervention.
We thank the KEMRI nurses at Kilifi hospital for their support during the long hours of monitoring. This paper is published with the permission of the Director of KEMRI, Dr D Koech. We also thank Professor BG Neville, Dr D Hanley, and Dr P Stephens for reviewing the manuscript. This work was supported by KEMRI and The Wellcome Trust, UK. Dr CRJC Newton holds an Advanced Training Fellowship in Tropical Medicine (18085), Dr K Marsh is a Wellcome Trust Senior Research Fellow in Clinical Science (031342) and Dr FJ Kirkham is supported by the Wellcome Trust (035352).

1 Sturchler D. How much malaria is there worldwide? Parasitology Today 1990;5:12.

2 Greenwood BM, Bradley AK, Greenwood AM, et al. Mortality and morbidity from malaria among children in a rural area of The Gambia, West Africa. Trans $R$ Soc Trop Med Hyg 1987;81:478-86.

3 Mendis KN, Carter R. Clinical disease and pathogenesis of malaria. Parasitology Today 1995;11:1-16.

4 Goitein KJ, Amit Y, Mussaffi H. Intracranial pressure in central nervous system infections and cerebral ischaemia of infancy. Arch Dis Child 1983;58:184-6.

5 Tasker RC, Matthew DJ, Helms P, Dinwiddie R, Boyd S. Tasker RC, Matthew DJ, Helms P, Dinwiddie R, Boyd S.
Monitoring in non-traumatic coma. Part I: invasive intracMonitoring in non-traumatic coma. Part I: invasive in
ranial measurements. Arch Dis Child 1988;63:888-94.

6 Rebaud P, Berthier JC, Hartemann E, Floret D. Intracranial pressure in childhood central nervous system infections Intensive Care Medicine 1988;14:522-5.

7 Mickell JJ, Reigel DH, Cook DR, Binda RE, Safar P. Intracranial pressure: monitoring and normalization therapy in children. Pediatrics 1977;59:606-13.

8 Minns RA. Infectious and parainfectious encephalopathies. In: Minns RA, ed. Problems of intracranial pressure in childhood. London: Mac Keith Press, 1991:170-282.

9 Kirkham FJ. Intracranial pressure and cerebral blood flow in non-traumatic coma in childhood. In: Minns RA, ed. Problems of intracranial pressure in childhood. London: Mac Keith Press, 1991:283-348.

10 Newton CR, Kirkham FJ, Winstanley PA, et al. Intracranial pressure in African children with cerebral malaria. Lancet 1991;337:573-6.

11 Waller D, Crawley J, Nosten F, Krishna S, White NJ. Intracranial pressure in childhood cerebral malaria. Trans $R$ Soc ranial pressure in childhood cer
Trop Med Hyg 1991;85:362-4.

12 Lewallen S, Taylor TE, Molyneux ME, Wills BA, Courtright $P$. Ocular fundus findings in Malawian children with cerebral malaria. Ophthalmology 1993;100:857-61.

13 Kwiatowski D, Molyneux M, Taylor T, Curtis N, Klein N. Cerebral malaria [letter]. Lancet 1991;337:1281-2.

14 Looaresuwan S, Wilairatana S, Krishna S, et al. Magnetic resonance imaging of the brain in patients with cerebral malaria. Clin Infect Dis 1995;21:300-9.

15 Warrell DA, Molyneux ME, Beales PF. Severe and complicated malaria. Trans $R$ Soc Trop Med Hyg 1990;84(suppl 2):1-65.

16 Lunberg N. Continuous recording and control of ventricular fluid pressure in neurosurgical practice. Acta Psychiatr Neurol Scand 1960;suppl 149:7-193.

17 Miller JD. Basic intracranial dynamics. In: Minns RA, ed. Miller JD. Basic intracranial dynamics. In: Minns RA, ed.
Problems of intracranial pressure in childhood. London: Mac Problems of intracranial p

18 Pariacz E. Introduction. In: Pariacz E, ed. ICP in infancy and childhood. Basel: Karger, 1982:1-7.

19 Seshia SS, Johnstone B, Kasian G. Non-traumatic coma in childhood clinical variables in prediction of outcome. Dev Med Child Neurol 1983;25:493-501

20 Newton CRJC, Marsh K, Peshu N, Kirkham FJ. Perturbation of cerebral hemodynamics in Kenyans with cerebral malaria. Pediatr Neurol 1996;15:41-9.

21 Walker O, Salako LA, Sowumni A, Thomas JO, Sodeine O, Bondi FS. Prognostic risk factors and post mortem findings in cerebral malaria in children. Trans $R$ Soc Trop Med Hyg 1992;86:491-3.

22 Goitein KJ, Fainmesser P, Sohmer H. Cerebral perfusion pressure and auditory brain-stem responses in childhood
CNS diseases. Am $\mathcal{F}$ Dis Child 1983;137:777-81.

23 Newton CRJC, Peshu N, Kendall B, et al. Brain swelling and ischaemia in Kenyans with cerebral malaria. Arch Dis Child 1994;70:281-7.

24 Meldrum BS, Horton RW. Physiology of status epilepticus in primates. Arch Neurol 1973;28:1-9.

25 Hudak ML, Koehler RC, Rosenberg AA, Traystman RJ, Jones DM. Effect of hematocrit on cerebral blood flow. Am f Physiol 1986;20:H63-70.

26 Grau GE, Taylor TE, Molyneux ME, et al. Tumor necrosis factor and disease severity in children with falciparum malaria. N Engl f Med 1989;320:1586-91.

27 Kwiatkowski D, Hill AV, Sambou I, et al. TNF concentration in fatal cerebral, non-fatal cerebral, and uncomplicated Plasmodium falciparum malaria. Lancet 1990;336:1201-4.

28 Krishna S, Waller DW, ter Kuile F, et al. Lactic acidosis and hypoglycaemic in children with severe malaria: pathophysiological and prognostic significance. Trans $R$ Soc Trop Med Hyg 1994;88:67-73.

29 Lassen NA. The luxury-perfusion syndrome and its possible relation to acute metabolic acidosis localised within the brain. Lancet 1966;ii: 1113-5.

30 Brown K, Steer C. Strategies in the management of children with acute encephalopathies. In: Gordon N, McKinlay I,
eds. Neurologically sick children: treatment and management. Oxford: Blackwell Scientific Publications, 1986:219-93. 
31 Mayer T, Walker ML. Emergency intracranial pressure monitoring in pediatrics: management of the acute coma of brain insult. Clin Pediatr (Phila) 1982;21:391-6.

32 Nussbaum E, Maggi JC. Intracranial pressure monitoring by subarachnoid bolt in comatose children. Clin Pediatr (Phila) 1985;24:329-30.

33 Warrell DA, Looareesuwan S, Warrell MJ, et al. Dexamethasone proves deleterious in cerebral malaria. A double-blind trial in 100 comatose patients. N Engl F Med 1982;306:313 319
34 Hoffman SL, Rustama D, Punjabi NH, et al. High-dose dexamethasone in quinine-treated patients with cerebral malaria: a double-blind, placebo-controlled trial. F Infect Dis 1988;158:325-31.

35 Kingston ME. Experience with urea in invert sugar for the treatment of cerebral malaria. $\mathcal{F}$ Trop Med Hyg 1971;74: 249-52.

36 Commey JO, Mills-Tetteh D, Phillips BJ. Cerebral malaria in Accra, Ghana. Ghana Med $\mathcal{F}$ 1980;19:68-72.

37 Commey JO. Is it cerebral malaria? Lancet 1984;ii:1037.

\section{Genetic immunisation}

The Brown-Norway rat is prone to atopy; after intraperitoneal challenge with allergen it produces lots if IgE, develops eosinophilia, and shows early and late bronchospasm. Research workers in Taiwan (Ching-Hsiang Hsu and colleagues, Nature Medicine 1996;2:540-4) injected a plasmid DNA encoding a house dust mite allergen into the muscles of such mice. They showed that the muscle cells then produced the allergen for at least six months and that the rats produced IgG but not IgE specific antibodies. When later challenged with the allergen they produced only $20 \%$ of the allergen specific IgE produced by control rats similarly challenged and, unlike control rats, they did not develop bronchospasm or release large amounts of histamine into their lungs. This inhibition of response was specific to the house dust mite allergen, the rats responding as usual to a different allergen. Furthermore the response inhibition was transferred to immunologically naive rats by injecting them with $\mathrm{CD} 8+\mathrm{T}$ cells from the experimental rats.

Intracellular and extracellular antigens are dealt with differently. Peptides from intracellular antigens are presented to CD8+T cells by major histocompatibility complex class I molecules present on all cells whereas those from extracellular antigens are presented to CD4+T cells by MHC class II molecules on specialised cells. This may explain why persuading somatic cells to produce an allergen might alter the immune response to that allergen.

There is much to be learned before this work can be translated to therapeutic use. There are fears of potential carcinogenesis because of interference with normal genes and it is not known how animals (or people) already sensitised to allergen would respond. It's fascinating, though, isn't it?

ARCHIVIST 